\title{
IJCIT
}

(Indonesian Journal on Computer and Information Technology)

Journal Homepage: http://ejournal.bsi.ac.id/ejurnal/index.php/ijcit

\section{Sistem Pendukung Keputusan Pemberian Program Bantuan Stimulan Perumahan Swadaya (BSPS) KemenPUPR}

\author{
Sefrika \\ Sistem Informasi Akuntansi, Universitas Bina Sarana Informatika \\ Jakarta, Indonesia \\ e-mail: sefrika.sfe@bsi.ac.id
}

\begin{abstract}
A B S T R A K
Sistem Pendukung keputusan adalah metode yang digunakan untuk membantu proses pengambilan keputusan secara akurat dan tepat. Sistem pendukung keputusan dengan metode TOPSIS adalah suatu metode yang dapat dilakukan dengan menguji sampel yang memiliki berbagai alternatif multi kriteria untuk mendapatkan hasil yang valid dan akurat. TOPSIS memberikan solusi alternatif yang dapat dipilih dengan memperhatikan jarak terpendek dari solusi ideal negatif dan positif. Program Bantuan Stimulan Perumahan Swadaya (BSPS) yang diberikan oleh Kementrian Pekerjaan Umum Dan Perumahan Rakyat (KemenPUPR) adalah sebuah program yang bertujuan untuk memberikan rumah layak huni bagi masyarakat. Penelitian ini bertujuan agar penerima bantuan program BSPS dapat disalurkan tepat sasaran kepada masyarakat yang berada di wilayah yang sangat membutuhkan. Penelitian ini dilakukan dengan cara melakukan analisa terkait siapa saja yang berhak menerima program bantuan BSPS agar penerima bantuan tepat sasaran sesuai dengan amanat undang-undang. Penelitian dilakukan terhadap lima sampel wilayah yaitu di Kecamatan Ciomas, Tamansari, Cigombong, Cijeruk dan Rancabungur yang berada di Kabupaten Bogor. Hasil penelitian mendapatkan data bahwa kriteria penerima program BSPS yang paling tepat adalah kriteria wilayah dengan kriteria kemiskinan yang tinggi.
\end{abstract}

Katakunci: BSPS, KemenPUPR, Sistem Pendukung Keputusan, TOPSIS

\begin{abstract}
A B S TRACTS
Decision Support System is a method used to help the decision making process accurately and precisely. Decision support system with TOPSIS method is a method that can be done by testing samples that have various multicriteria alternatives to get valid and accurate results. TOPSIS provides an alternative solution that can be chosen by considering the shortest distance from the ideal negative and positive solution. The Self-Help Housing Stimulant Assistance Program (BSPS) provided by the Ministry of Public Works and Housing (KemenPUPR) is a program that aims to provide decent housing for the community. This study aims to ensure that recipients of BSPS program assistance can be channeled on target to communities in areas that are most in need. This research was carried out by analyzing who was entitled to receive the BSPS assistance program so that the recipients of the assistance were on target in accordance with the mandate of the law. The study was conducted on five sample regions, namely in Ciomas, Tamansari, Cigombong, Cijeruk and Rancabungur Subdistricts in Bogor Regency. The results of the study found that the most appropriate criteria for recipients of the BSPS program were regional criteria with high poverty criteria.
\end{abstract}

Keywords: BSPS, Decision Support System, KemenPUPR, TOPSIS 


\section{PENDAHULUAN}

Program Bantuan Stimulan Perumahan Swadaya (BSPS) yang diberikan oleh Kementrian Pekerjaan Umum Dan Perumahan Rakyat (KemenPUPR) adalah sebuah program yang bertujuan untuk memberikan rumah layak huni bagi masyarakat. Program ini dikenal oleh masyarakat luas sebagai program bedah rumah. Landasan utama penyaluran BSPS adalah Undang-undang Nomor 1 tahun 2011 tentang Perumahan dan Kawasan Permukiman Pasal 54 ayat (3) huruf b yang menyatakan bahwa bantuan pembangunan rumah bagi MBR dari pemerintah dapat berupa stimulan rumah swadaya. Selain itu juga terdapat dalam Amanat RPJMN 2015-2019 tentang Peningkatan Kualitas dan Pembangunan Baru. Program rumah swadaya dalam hal ini Bantuan Stimulan Perumahan Swadaya (BSPS) didasarkan pada Peraturan Menteri Pekerjaan Umum dan Perumahan Rakyat (Permen PUPR) Nomor:39/PRT/M/2015 yang sebelumnya diatur dengan Peraturan Menteri Perumahan Rakyat (Permen PERA) Nomor: 06 TAHUN 2013.

Setiap penerima Bantuan Stimulan Perumahan Swadaya (BSPS) ditetapkan dengan Surat Keputusan oleh Pejabat Pembuat Komitmen Bantuan Rumah Swadaya (PPK-BRS) Wilayah atas dasar usulan yang telah dilakukan verifikasi atas kelengkapan administrasi (KTP, kepemilikan lahan/tanah, keterangan penghasilan dan lain - lain). Namun untuk menentukan kelayakan penerima bantuan program BSPS perlu dilakukan analisa lebih lanjut agar pemberian dana program BSPS tepat sasaran. Penelitian ini bertujuan untuk melakukan analisa penerima program BSPS dengan metode TOPSIS agar dapat membantu memberikan keputusan yang tepat bagi calo penerima bantuan sesuai dengan kriteria yang sudah ditentukan.

Metode TOPSIS (Technique for Order Preference by Similarity to Ideal Solution) merupakan salah satu metode pengambilan keputusan multikriteria yang didasarkan pada konsep bahwa alternatif yang terbaik tidak hanya memiliki jarak terpendek dari solusi ideal positif tetapi juga memiliki jarak terpanjang dari solusi ideal negative (Benning, Astuti, \& Khairina, 2015).

Penelitian yang telah dilakukan terhadap sampel 20 stasiun dan multikriteria yang di uji, maka di dapatkan nilai 0.56 dari variabel kriteria
2 yaitu lokasi (C2). Maka untuk pembelian vending machine di stasiun yang di analisa berdasarkan metode TOPSIS dapat digunakan pemilihan kriteria ideal untuk pembelian vending machine berdasarkan kriteria pemilihan lokasi stasiun (Alawiah \& Susilowati, 2018).

Berdasarkan hasil penelitian dapat disimpulkan didapatkan 2 kondisi rumah sehat dan 8 kondisi rumah tidak sehat; Metode TOPSIS dapat diterapkan untuk menentukan prioritas rumah tidak sehat yang menghasilkan alternatif ke-2 atas nama (Sutardi) dengan nilai preferensi (1) dinyatakan sebagai prioritas utama untuk kondisi rumah tidak sehat; Hasil perhitungan sistem telah divalidasi dengan perhitungan manual didapatkan hasil yang sama, dan dapat dikatakan bahwa sistem yang telah menerapkan metode TOPSIS untuk menentukan prioritas rumah tidak sehat telah berjalan dengan baik dan sesuai (Chamid, 2016).

Sistem pendukung keputusan untuk rekomendasi kelulusan peserta mahasiswa sidang skripsi dengan menggunakan AHPTOPSIS telah dihasilkan. SPK ini dapat memberikan akurasi berdasarkan jarak Hamming sebesar 96,2\% dan jarak Euclidean 0,8096 untuk 95sampel data mahasiswa antara tahun 2014-2016 sehingga dapat diterapkan untuk merekomendasikan kelulusan peserta mahasiswa sidang skripsi (Sari, Windarto, Hartama, \& Solikhun, 2018).

Metode yang dipakai dalam sistem pendukung keputusan pemilihan laptop ini adalah Technique For Order Preference by Similarity to Ideal Solution (TOPSIS). TOPSIS merupakan suatu bentuk metode pendukung keputusan yang didasarkan pada konsep bahwa alternatif yang terbaik tidak hanya memiliki jarak terpendek dari solusi ideal positif tetapi juga memiliki jarak terpanjang dari solusi ideal negative yang dalam hal ini akan memberikan rekomendasi pemilihan laptop yang sesuai dengan yang diharapkan. Konsep ini banyak digunakan untuk menyelesaikan masalah keputusan secara praktis (Kurniasih, 2013).

Sistem pendukung keputusan untuk rekomendasi kelulusan peserta mahasiswa sidang skripsi dengan menggunakan AHP-TOPSIS telah dihasilkan. SPK ini dapat memberikan akurasi berdasarkan jarak Hamming sebesar 96,2\% dan jarak Euclidean 0,8096 untuk 95 sampel data mahasiswa antara tahun 2014-2016 sehingga dapat diterapkan untuk merekomendasikan kelulusan peserta mahasiswa sidang skripsi (Sari et al., 2018). 
Metode TOPSIS digunakan karena metode ini dapat menyelesaikan permasalahan multikriteria dengan menawarkan berbagai solusi alternative untuk memecahkan masalah. Hasil penelitian mendapatkan nilai preferensi 0,58 dari kriteria C2 yaitu memiliki rumah kepemilikan atas nama sendiri. Oleh karena itu, system keputusan yang dapat dilakukan untuk memberikan bantuan program RS_RUTILAHU dapat mempertimbangkan aspek kepemilikan rumah atas nama sendiri (Dengan et al., 2019).

Metode TOPSIS ini digunakan dengan berbagai pilihan multikriteria. Topsis menggunakan prinsip bahwa alternatif yang terpilih harus mempunyai jarak terdekat dari solusi ideal positif dan jarak terpanjang (terjauh) dari solusi ideal negative. Hasil penelitian mendapatkan nilai preferensi bahwa alternative untuk memilih jenis kendaraan keluarga harus mempertimbangkan aspek harga sebagai yang utama, disusul oleh fitur, kapasitas dan kecepatan kendaraan. Hasil penelitian dapat digunakan sebagai referensi pemilihan jenis kendaran mobil keluarga (Sefrika, 2018).

Sistem pendukung keputusan merupakan sistem informasi interaktif yang menyediakan informasi, pemodelan, dan pemanipulasi data. Sistem ini digunakan untuk membantu pengambilan keputusan dalam situasi yang semiterstruktur dan situasi yang tidak terstruktur (Hutasoit \& Wanto, 2018).

Sistem pendukung keputusan (SPK) adalah sebuah sistem yang dapat membantu seseorang dalam mengambil keputusan dari berbagai jenis pilihan yang dilakukan secara akurat dan sesuai dengan sasaran yang diinginkan. Banyak permasalahan yang dapat diselesaikan dengan menggunakan sistem pendukung keputusan (Fitriana, Harliana, \& Handaru, 2018).

Salah satu metode yang dapat digunakan dalam pengambilan keputusan untuk penentuan karyawan kontrak menjadi karyawan tetap yaitu dengan metode TOPSIS (Techinique for Order Preference by Similarity to Ideal Solution) adalah didasarkan pada konsepnya dimana, alternatif terpilih yang baik tidak hanya memiliki jarak terpendek dari solusi ideal positif tetapi juga memiliki jarak terpanjang dari solusi ideal negatif. Konsepnya sederhana dan mudah dipahami, komputasinya efisien, dan memiliki kemampuan untuk mengukur kinerja relatif dari alternatif-alternatif keputusan dalam bentuk matematis yang sederhana (Mallu \& Keputusan, 2015).

\section{METODE PENELITIAN}

Tahapan penelitian yang dilakukan adalah sebagai berikut:

a. Menganalisa kriteria subjek penerima bantuan BSPS

b. Menganalisa kriteria objek bantuan BSPS

c. Mendefinisikan kebutuhan

d. Melakukan analisa dengan metode TOPSIS . Analisa dilakukan dengan cara menentukan variabel yang akan digunakan. Penelitian dilakukan terhadap 5 sampel wilayah yang dibagi menjadi 5 kriteria. Kecamatan Ciomas untuk variabel A1, Kecamatan Tamanasari untuk variabel A2, Kecamatan Cigombong untuk variabel $A 3$, Kecamatan Cijeruk untuk variabel $A 4$, Kecamatan Rancabungur untuk variabel $A 5$.

e. Menganalisa matriks keputusan ternormalisasi

f. Menganalisa matriks ternormalisasi

g. Menganalisa matriks ternormalisasi terbobot

h. Mencari solusi ideal negative dan solusi ideal positif

i. Menghitung nilai alternatif

\section{HASIL DAN PEMBAHASAN}

\section{A. Kriteria Subjek Penerima Bantuan BSPS}

Berdasarkan data KemenPUPR, berikut adalah data subjek penerima bantuan BSPS yaitu:

1) WNI

2) MBR dengan penghasilan dibawah UMP ratarata nasional

3) Sudah berkeluarga

4) Memiliki atau menguasai tanah

5) Belum memiliki rumah atau memiliki dan menghuni rumah tidak layak huni

6) Belum pernah menerima bantuan perumahan dari pemerintah

7) Didahulukan yang memiliki rencana pembangunan/peningkatan kualitas rumah, dibuktikan dengan memiliki tabungan bahan bangunan, telah memulai pembangunan rumah sebelum memperoleh bantuan, memiliki aset lain yang dapat dijadikan dana tambahan BSPS serta Memiliki tabungan uang yang dijadikan dana tambahan BSPS

8) Bersungguh-sungguh mengikuti Program BSPS

9) Dapat bekerja secara berkelompok 


\section{B. Kriteria Objek Bantuan BSPS}

Berikut adalah kriteria objek penerima BSPS berdasarkan data dari KemenPUPR yaitu:

1) Rumah tidak layak huni yang berada di atas tanah:

a. Dikuasai secara fisik dan jelas batasbatasnya

b. Bukan merupakan tanah warisan yang belum dibag

c. Tidak dalam status sengketa, dan

d. Penggunaannya sesuai dengan rencana tata ruang

2) Bangunan yang belum selesai dari yang sudah diupayakan oleh masyarakat sampai paling tinggi struktur tengah dan luas lantai bangunan paling tinggi $45 \mathrm{~m} 2$

3) Terkena kegiatan konsolidasi tanah atau relokasi dalam rangka peningkatan kualitas perumahan dan kawasan permukiman, dan/atau

4) Terkena bencana alam, kerusuhan sosial dan/atau kebakaran

\section{Analisa Kebutuhan}

Berdasarkan data di atas, diperlukan sebuah analisa terkait siapa saja yang berhak menerima program bantuan BSPS agar penerima bantuan tepat sasaran sesuai dengan amanat undang-undang. Kebutuhan yang diperlukan untuk analisa dengan metode TOPSIS yaitu:

a. Data penerima bantuan

Analisa sementara dilakukan di provinsi Jawa Barat khsususnya Kabupaten Bogor yang meliputi 5 kecamatan yaitu Ciomas, Tamansari, Cigombong, Cileungsi dan Bojong Gede

b. Kriteria kelayakan

Tabel 1. kriteria kelayakan

\begin{tabular}{ccc}
\hline No & Kriteria & Bobot nilai (Wi) \\
\hline 1 & Sangat Baik & 5 \\
2 & Baik & 4 \\
3 & Cukup & 3 \\
4 & Buruk & 2 \\
5 & Sangat Buruk & 1 \\
\hline
\end{tabular}

Tabel 2. Data Wilayah

\begin{tabular}{ll}
\hline Wilayah & Kriteria \\
\hline Ciomas & A1 \\
Tamansari & A2 \\
Cigombong & A3 \\
Cijeruk & A4 \\
Ranca Bungur & A5 \\
\hline
\end{tabular}

\section{Analisa dengan Metode TOPSIS}

Metode TOPSIS adalah metode dengan menggunakan analisa terhadap multikriteria. Tujuannya agar penelitian ini dapat melakukan analisa dari berbagai alternative yang ditawarkan. Untuk memudahkan penilaian, maka ditentukan kriteria penilaian yaitu:

1) Tingkat Kemiskinan (C1)

2) Jumlah Rumah Tidak Layak Huni (C2)

3) Jumlah Kekurangan Rumah (C3)

4) Daerah Tertinggal (C4)

5) Perbatasan Negara (C5)

\section{E. Analisa matriks keputusan ternomalisasi}

Tabel 3. Nilai bobot setiap kriteria

\begin{tabular}{llllll}
\hline Kriteria & C1 & C2 & C3 & C4 & C5 \\
\hline Ciomas (A1) & 3 & 3 & 3 & 4 & 4 \\
Tamansari (A2) & 2 & 2 & 2 & 3 & 2 \\
Cigombong (A3) & 2 & 2 & 2 & 2 & 4 \\
Cileungsi (A4) & 4 & 4 & 4 & 3 & 4 \\
Bojong Gede (A5) & 4 & 4 & 4 & 3 & 4 \\
\hline
\end{tabular}

Tabel 4. Hasil Nilai bobot kriteria

\begin{tabular}{ccccc}
\hline C1 & C2 & C3 & C4 & C5 \\
\hline 2 & 3 & 3 & 3 & 4 \\
\hline
\end{tabular}

Tabel 5. Nilai Ternormalisasi

\begin{tabular}{cccccc}
\hline Kriteria & C1 & C2 & C3 & C4 & C5 \\
\hline A1 & 3 & 3 & 3 & 4 & 4 \\
A2 & 2 & 2 & 2 & 3 & 2 \\
A3 & 2 & 2 & 2 & 2 & 4 \\
A4 & 4 & 4 & 4 & 3 & 4 \\
A5 & 4 & 4 & 4 & 3 & 4 \\
\hline Hasil & & & & & \\
pangkat & 49 & 49 & 49 & 47 & 68 \\
kriteria & & & & & \\
\hline $\begin{array}{c}\text { Akar hasil } \\
\text { pangkat }\end{array}$ & 7 & 7 & 7 & 6.8 & 8.2 \\
criteria & & & & & \\
\hline
\end{tabular}

\section{F. Matriks Ternormalisasi}

Tabel 6. Hasil akhir data normalisasi

\begin{tabular}{lrrrrr}
\hline & \multicolumn{1}{c}{ C1 } & \multicolumn{1}{l}{ C2 } & C3 & C4 & \multicolumn{1}{l}{ C5 } \\
\hline A1 & 0.42 & 0.42 & 0.42 & 0.58 & 0.48 \\
A2 & 0.28 & 0.28 & 0.28 & 0.44 & 0.24 \\
A3 & 0.28 & 0.28 & 0.28 & 0.29 & 0.48 \\
A4 & 0.57 & 0.57 & 0.57 & 0.44 & 0.48 \\
A5 & 0.57 & 0.57 & 0.57 & 0.44 & 0.48 \\
\hline
\end{tabular}


G. Analisa matriks ternormalisasi terbobot Rumus:

$y_{i j}=w_{i} r_{i j} ;$ dengan $i=1,2, \ldots, m ;$ dan $j=1,2, \ldots, n$

Tahapan selanjutnya adalah membuat table normalisasi berbobot yang didapatkan dari data normalisasi di atas $\mathrm{x}$ bobot kriteria

Tabel 7. Nilai bobot setiap kriteria

\begin{tabular}{ccccc}
\hline $\mathrm{C} 1$ & $\mathrm{C} 2$ & $\mathrm{C} 3$ & $\mathrm{C} 4$ & $\mathrm{C} 5$ \\
\hline 2 & 3 & 3 & 3 & 4 \\
\hline
\end{tabular}

Tabel 8. Hasil perhitungan normalisasi $x$ bobot

\begin{tabular}{cccccc}
\multicolumn{7}{c}{ kriteria } \\
\hline Kriteria & C1 & C2 & C3 & C4 & C5 \\
\hline A1 & 0.84 & 1,26 & 1,26 & 1,74 & 1,92 \\
A2 & 0.56 & 0,84 & 0,84 & 1,32 & 0,96 \\
A3 & 0.56 & 0,84 & 0,84 & 0,87 & 1,92 \\
A4 & 0.38 & 1,71 & 1,71 & 1,32 & 1,92 \\
A5 & 1,14 & 1,71 & 1,71 & 1,32 & 1,92 \\
\hline
\end{tabular}

H. Analisa solusi ideal negative dan solusi ideal positif

$$
\text { Rumus } \begin{aligned}
& A^{+}=\max \left(y_{1}^{+}, y_{2}^{+}, \ldots, y_{n}^{+}\right) \\
& A^{-}=\max \left(y_{1}^{-}, y_{2}^{-}, \ldots, y_{n}^{-}\right)
\end{aligned}
$$

Tabel 9. Nilai solusi ideal positif $(A+)$ dan negative (A-)

\begin{tabular}{cccccc}
\hline Kriteria & C1 & C2 & C3 & C4 & C5 \\
\hline A1 & 0.84 & 1,26 & 1,26 & 1,74 & 1,92 \\
A2 & 0.56 & 0,84 & 0,84 & 1,32 & 0,96 \\
A3 & 0.56 & 0,84 & 0,84 & 0,87 & 1,92 \\
A4 & 0.38 & 1,71 & 1,71 & 1,32 & 1,92 \\
A5 & 1,14 & 1,71 & 1,71 & 1,32 & 1,92 \\
\hline Min & 0.38 & 0.84 & 0.84 & 0.87 & 0.96 \\
\hline Maks & 1,14 & 1.71 & 1.71 & 1.74 & 1.92 \\
\hline
\end{tabular}

I. Analisa nilai alternatif

$V_{i}=\frac{D_{i}^{-}}{D_{i}^{-}+D_{i}^{+}}$, dimana $i=1,2,3, \ldots m$

Tabel 10. Nilai D+ dan D-

\begin{tabular}{cc}
\hline Nilai D+ & Nilai D- \\
\hline 126,19 & 148,70 \\
222,83 & 244,23 \\
222,83 & 244,23 \\
207,15 & 230,80 \\
290,97 & 297,30 \\
\hline
\end{tabular}

Tabel 11. Preferensi alternative

\begin{tabular}{ccc}
\hline Kriteria & Nilai Vi=(Di-/(Di-+Di+) & Nilai D- \\
\hline C1 & $(148,70) /$ & \\
& $(148,70+126,19)$ & 0.54 \\
C2 & $(244,23) /$ & \\
& $(244,23+222,83)$ & 0.52 \\
C3 & $(244,23) /$ & \\
& $(244,23+222,83)$ & 0.52 \\
C4 & $(230,80) /$ & \\
& $(230,80+207,15)$ & 0.52 \\
C5 & $(297,30) /$ & \\
& $(297,30+290,97)$ & 0.40 \\
\hline
\end{tabular}

\section{KESIMPULAN}

Berdasarkan penelitian yang telah dilakukan terhadap 5 Kecamatan di daerah Kabupaten Bogor, maka didapatkan nilai preferensi alternatif sebanyak 0,54 dengan kriteria $\mathrm{C} 1$ yaitu tingkat kemiskinan.

Berdasarkan hal tersebut, maka kriteria penerima Program Bantuan Stimulan Perumahan Swadaya (BSPS) yang diberikan oleh Kementrian Pekerjaan Umum Dan Perumahan Rakyat (KemenPUPR) yang dilakukan uji terhadap 5 Kecamatan di Kabupaten Bogor, maka kriteria penerima bantuan utama harus diberikan kepada Kecamatan dengan jumlah penduduk miskin terbanyak.

Hasil uji coba bisa dilakukan terhadap wilayah lain yang ada di Kota dan Kabupaten serta Provinsi seluruh Indonesia dengan jumlah sampe uji yang lebih banyak.

\section{REFERENSI}

Alawiah, E. T., \& Susilowati, S. (2018). Sistem Pendukung Keputusan Pembelian Vending Machine Dengan Metode TOPSIS Studi Kasus PT . KAI Commuter Jabodetabek. 3(2), 208-215.

Benning, B. A., Astuti, I. F., \& Khairina, D. M. (2015). KOMPUTER DENGAN METODE TOPSIS ( Studi Kasus : CV . Triad ). Jurnal Informatika Mulawarman, 10(2), 1-7.

Chamid, A. A. (2016). Prioritas Kondisi Rumah. Jurnal SIMETRIS, 7(2), 537-544.

Dengan, R., Topsis, M., Desa, P., Ciomas, K., 
Creative, L., \& Internasional, C. A. (2019). SISTEM PENDUKUNG KEPUTUSAN PEMBERIAN BANTUAN RS-. 16(1), 73-78.

Fitriana, A. N., Harliana, H., \& Handaru, H. (2018). Sistem Pendukung Keputusan Untuk Menentukan Prestasi Akademik Siswa dengan Metode TOPSIS. Creative Information Technology Journal, 2(2), 153. https://doi.org/10.24076/citec.2015v2i2. 45

Hutasoit, R. A., \& Wanto, A. (2018). ANALISA PEMILIHAN BARISTA DENGAN MENGGUNAKAN METODE TOPSIS ( STUDI KASUS : MO COFFEE ). 2, 256-262.

Kurniasih, D. L. (2013). SISTEM PENDUKUNG KEPUTUSAN PEMILIHAN LAPTOP DENGAN METODE TOPSIS Diterbitkan Oleh: STMIK Budi Darma Medan Diterbitkan Oleh: STMIK Budi Darma
Medan. III(April), 6-13.

Mallu, S., \& Keputusan, S. P. (2015). Sistem pendukung keputusan penentuan karyawan kontrak menjadi karyawan tetap menggunakan metode topsis. I(2), 36-42.

Sari, D. R., Windarto, A. P., Hartama, D., \& Solikhun, S. (2018). Sistem Pendukung Keputusan untuk Rekomendasi Kelulusan Sidang Skripsi Menggunakan Metode AHP-TOPSIS. Jurnal Teknologi Dan Sistem Komputer, 6(1), 1. https://doi.org/10.14710/jtsiskom.6.1.20 18.1-6

Sefrika, S. S. (2018). Sistem Pendukung Keputusan Untuk Pemilihan Kendaraan Mobil Keluarga Dengan Metode Topsis. Jurnal Teknologi Informasi MURA, 10(2), 69.

https://doi.org/10.32767/jti.v10i2.356 